\title{
perspectives:
}

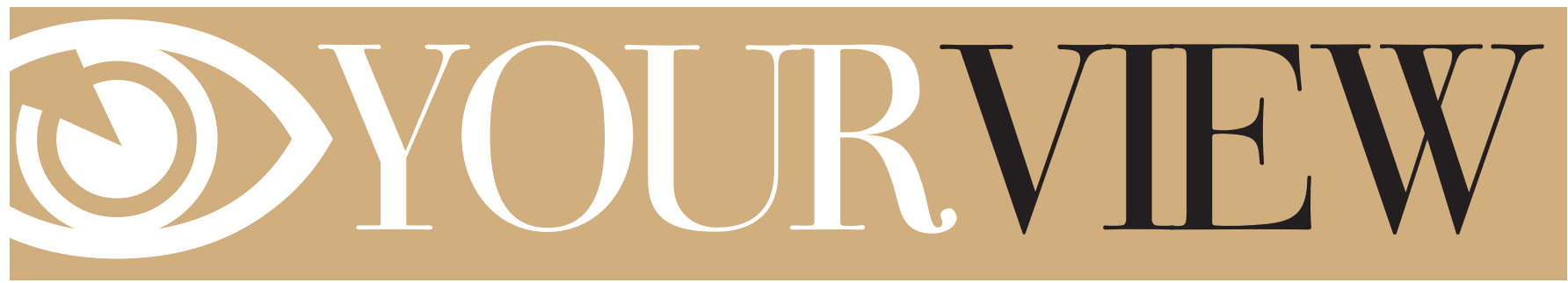

compiled by Julie Ferry

\section{Do you think the dental team should be more involved in the vocational training of dentists?}

\section{Dental nurse}

Lisa Dugan, dental nurse in the community dental service at Gosport Health Centre.

'In the community dental service we do get the whole dental team involved in the vocational training of dentists anyway. We use our therapists and nurses to help them when it comes to their training year and so we get quite a good insight into it. If nurses were to get involved in a more formal way, I think it would really depend on the nurse that you put with the VDP. If you are using the same qualified, experienced nurse all the time then I think it would be a good idea as you build up a good bond. On the other side you have to look at the problems that could arise if you put a less experienced nurse with them. That is why we put long-standing nurses with VDPs here already.'

\section{Hygienist}

Joanne Wood, hygienist at five different practices in the West Midlands. 'I think it may help the VDP to appreciate the valuable roles that every member of the dental team plays and also how each member interacts with each other to ensure the smooth running of the practice. They would have a better understanding of all the difficult tasks that everybody has in the work place and to see how it all fits together. The only problem with making it a formal thing is how involved people would be and at what level. I think it also depends on the individual practice as well as to how they would deal with it. The main obstacle is how to implement it in a way that will make sure it is successful. Overall though I think the idea is a good one.'

\section{Practice Manager}

\section{Bridget Morgan-Sagar, practice manager at Acorn Dental Health} in Southampton.

'In one way it would be good to have more of a team approach to vocational training. However, to be quite honest I don't think some of the dental team would be qualified enough to take on the extra responsibility. We have about half a dozen dental nurses and I don't think they would be able to guide VDPs in a formal way. At the moment I have to help VDPs with various things. They are taught one way but it isn't always the most practical way of doing things.'
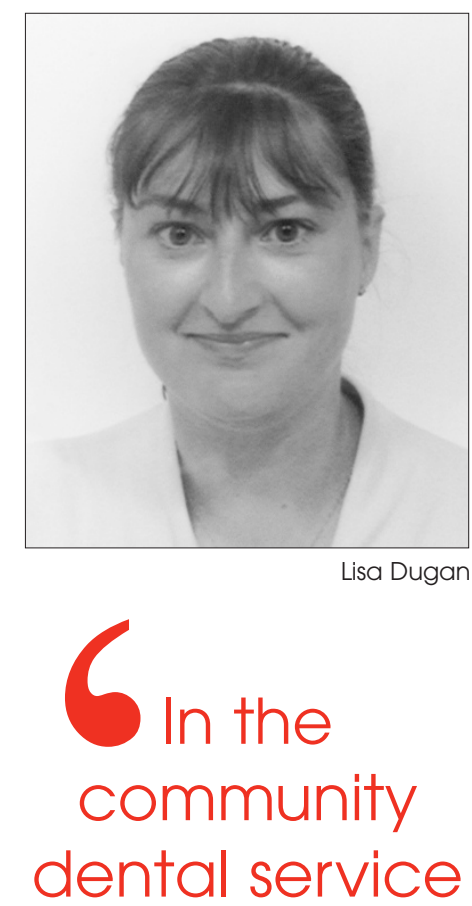

we get the whole dental team involved in the vocational training of dentists 


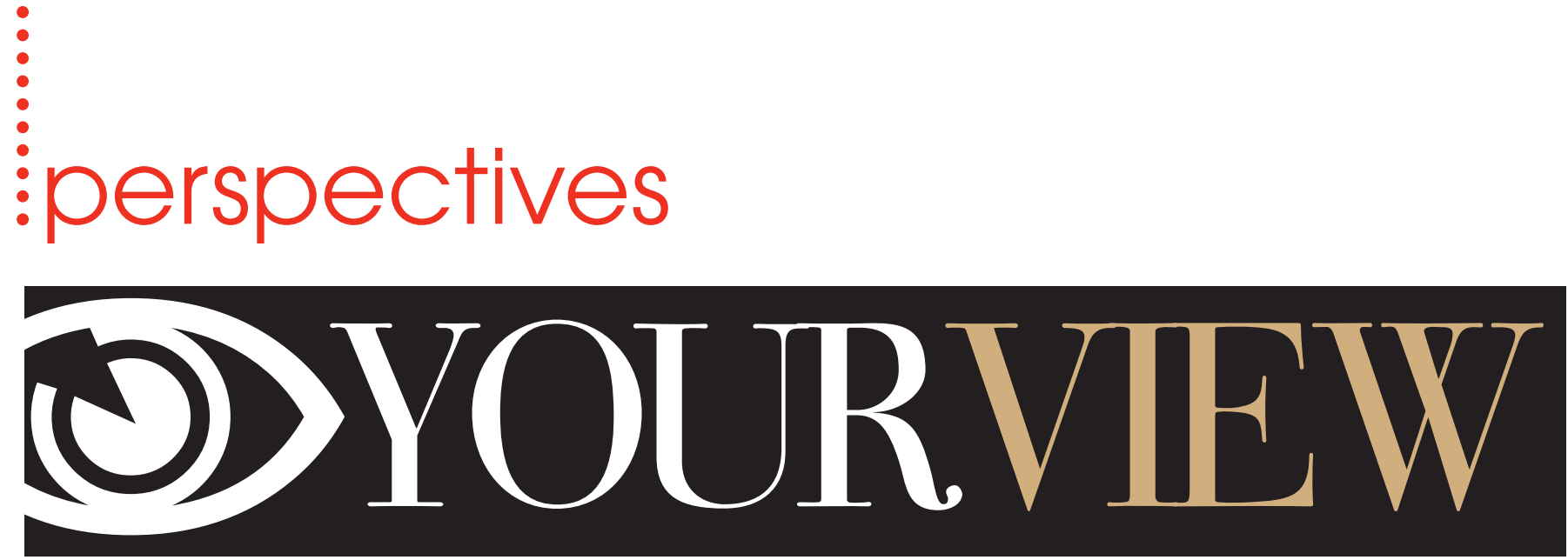

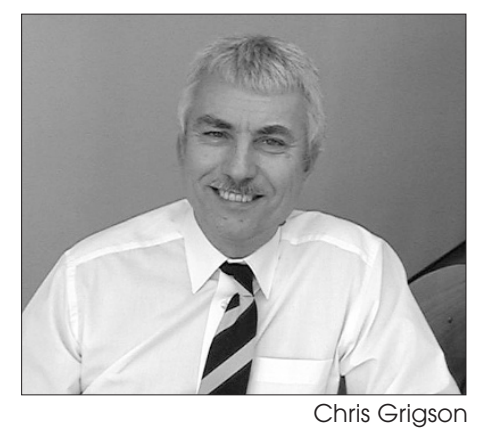

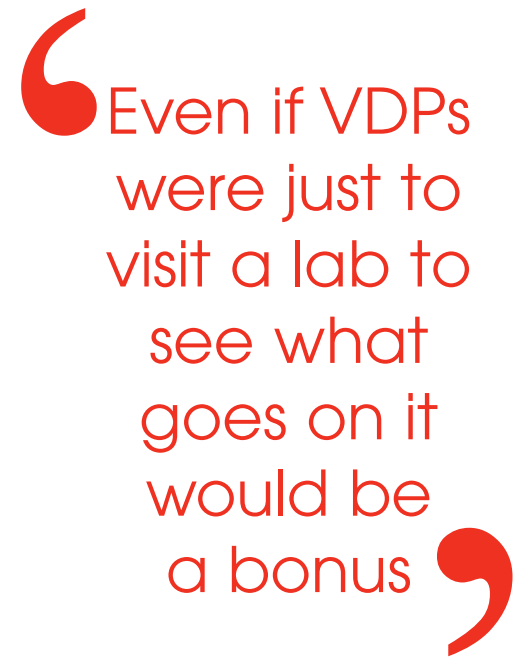

\section{Technician}

Chris Grigson, teacher of dental technology at Lambeth College in London.

'I worked in industry before coming into education and I think it is very important that there is this development of the whole team. The fact that at the moment so little dental technology is carried out by undergraduate dentists, some knowledge of what goes on in the dental laboratory is vital. It can help to improve communication between the laboratory and the clinic, something that often breaks down, and also helps both sides to understand what we are trying to achieve. Even if VDPs were just to visit a lab to see what goes on it would be a bonus and if they had time for some limited hands on training from us that would be good as well.'

\section{Therapist}

\section{Amanda Tyman is a therapist who works with a range of dental service} providers in West Yorkshire.

'I think participating in vocational training for team members is essential to fulfil their professional growth and future success. Much training is provided in the workplace and through other institutions throughout our careers, all are necessary to share our skills and dedication with our employers. Most dental service providers participate in regular peer reviews and CPD, however commitment to the training is dependant on financing, time factors and staffing, as time is money. Job satisfaction is assured when members have interactive, varied and challenging roles with good team relationships, which vocational training can provide. Finally, a successful training practice is only as successful as the team.'

\section{Receptionist}

Jenny Taylor is a receptionist at St James' Dental Practice in Gloucester. 'At our practice the whole team works closely with the VDP and it works really well. However, on reception we don't have a lot to do with them apart from working on the computer system and having to ask them questions about appointments sometimes. We could help to train VDPs on the computer but that is the same with any new dentist that joins the practice. I'm not sure that it would be a good idea to be formally involved in vocational training, as a receptionist we don't work closely enough with the VDP'

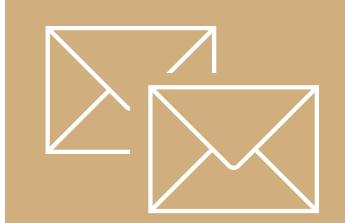

Our regular perspectives section is your chance to share your views with your colleagues. Please send your comments on the issues that interest you to: Perspectives, Vital magazine, BDJ, Nature Publishing Group, 4-6 Crinan Street, London N1 9XW OR email vitaleditorial@nature.com 